\title{
Individual-based simulations of larval fish feeding in turbulent environments
}

\author{
Patrizio Mariani ${ }^{1, *}$, Brian R. MacKenzie ${ }^{1}$, Andre W. Visser ${ }^{1}$, Vincenzo Botte ${ }^{2}$ \\ ${ }^{1}$ Danish Institute for Fisheries Research, Technical University of Denmark, Kavalergården 6,2920 Charlottenlund, Denmark \\ ${ }^{2}$ Laboratory of Biological Oceanography, Zoological Station 'A. Dohrn,'Villa Comunale 1,80100 Napoli, Italy
}

\begin{abstract}
We used an individual-based model coupled to a realistic turbulence flow field to assess the effects of a wide range of turbulence levels on encounter rate $(E)$, pursuit success and ingestion rate in fish larvae. We parameterized the model for larvae of Atlantic cod Gadus morhua and evaluated how the geometry of their prey search volume (hemisphere, wedge) affected feeding rates. We then compared model outputs with feeding rates for cod larvae in previous laboratory and field studies. Search volume is smaller and $E$ is lower for wedge searchers than hemisphere searchers. However, as turbulence increases, larvae encounter more prey but pursuit success decreases exponentially (relative to calm water), yielding a dome-shaped relationship between turbulence and ingestion rate. These results are robust to search volume geometry (wedge or hemisphere). The increase in ingestion rates at moderate turbulence for wedge searchers (relative to calm water rates) was higher than for hemisphere searchers. However, model results derived using hemisphere geometry are consistent with previous laboratory and field observations of cod larvae in turbulent environments. Cod larvae observed in a field study on Georges Bank in 1993-1994 could feed at rates which corresponded with observed growth rates if they behaved as hemispherical searchers and consumed a diet consisting of relatively large prey (e.g. copepodites and adults of Pseudocalanus); if they used wedgeshaped volumes, their ingestion and growth rates would have been ca. $80 \%$ lower, resulting in higher mortality. Models like those developed here will increase future understanding of factors affecting larval feeding rates and dietary composition.
\end{abstract}

KEY WORDS: Feeding $\cdot$ Ingestion $\cdot$ Encounter $\cdot$ Pursuit $\cdot$ Turbulence $\cdot$ Cod larvae $\cdot$ Growth $\cdot$ Predation

\section{INTRODUCTION}

The feeding of larval fish in the sea is influenced by ocean turbulence via several direct and indirect mechanisms. These effects include changes in (1) the production, concentration and distribution of prey (Kiørboe 1993, Bakun 1996), (2) vertical distributions of larvae (Heath et al. 1988, Franks 2001) and (3) the probabilities of encounter, pursuit and capture of prey by individual larvae (Dower et al. 1997, MacKenzie 2000). All of these processes vary with the intensity of turbulence in highly nonlinear ways and often in opposing directions. These responses of biological and physical processes to ocean turbulence complicate attempts to predict and understand how variations in turbulence affect larval fish ecology-in particular, the feeding success of larvae (Dower et al. 1997, MacKenzie 2000, Porter et al. 2005).

In the present study, we develop and apply new individual-based modelling approaches to investigate feeding processes of individual fish larvae in turbulent environments. These models are then combined with a realistic simulation of ocean turbulence at scales relevant to larval fish feeding. Previous modelling studies (Table 1) have used analytical modelling approaches forced by bulk-average turbulent dissipation rates and have demonstrated that encounter rates $(E)$ increase with turbulence intensity, but that overall ingestions rates have a dome-shaped relationship to turbulence (Matsushita 1992, MacKenzie et al. 1994). These theoretical models have experimental support (Landry et al. 1995, MacKenzie \& Kiørboe 1995, MacKenzie \& 
Table 1. Meta-data of the development of modelling approaches for investigating predation by zooplankton and fish larvae in calm and turbulent environments. $\varepsilon$ : dissipation rate; $\operatorname{Re}_{\lambda}$ : Reynolds number

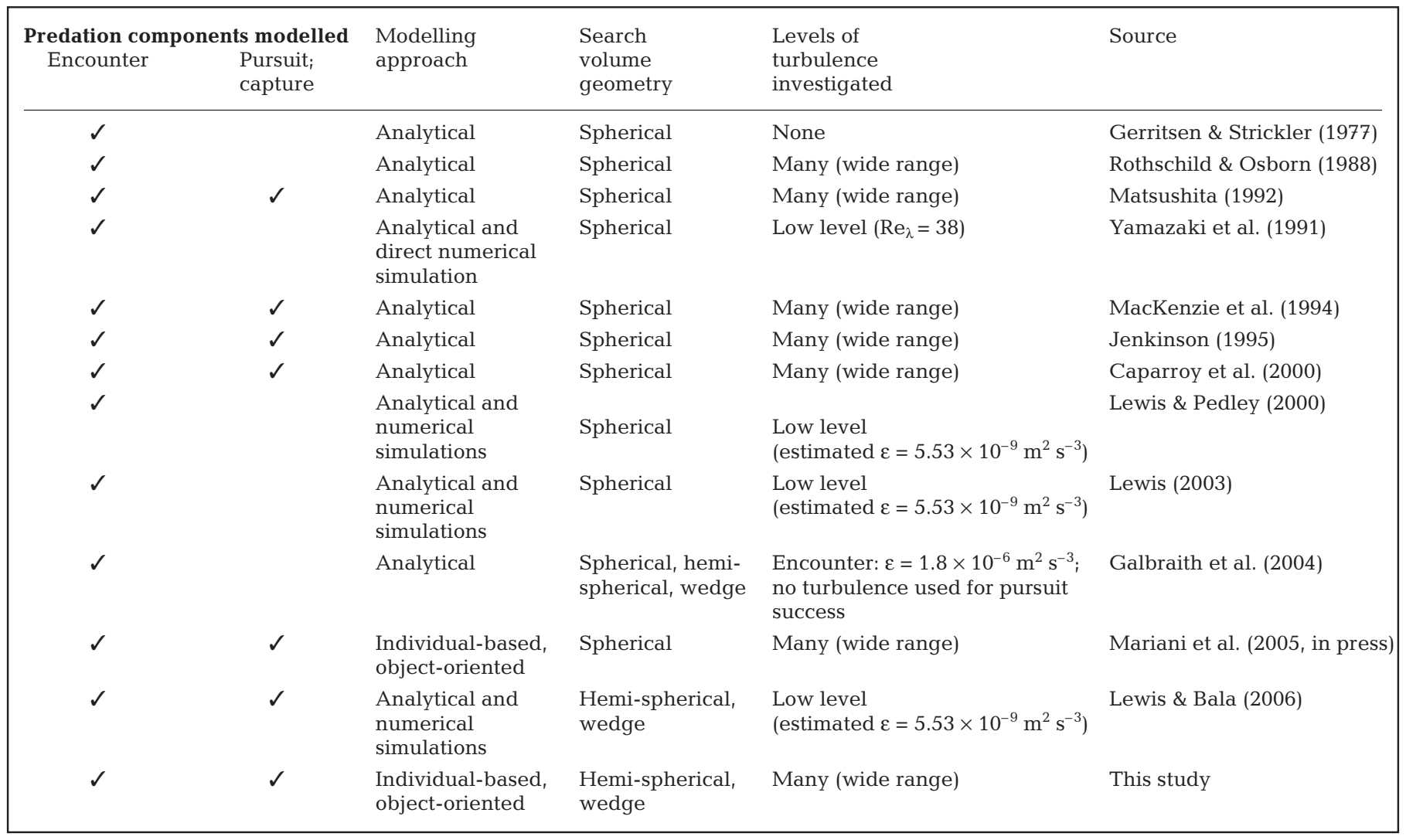

Kiørboe 2000, Utne-Palm \& Stiansen 2002). However, this type of modelling framework becomes impractical when analyses involve more complex aspects of organisms' feeding behaviour (Mariani et al. 2005), e.g. typical swimming and search behaviour (swim durations and frequencies, turn angles) of fish larvae, the swimming and escape behaviour of their prey, the intermittent nature of realistic turbulence.

We use our new models initially to investigate whether they yield comparable results to those seen in previous theoretical and experimental studies. We then explore the sensitivity of larval feeding to assumptions regarding the shape of the search volume of larval fishes. Early larval feeding behaviour studies (Rosenthal \& Hempel 1970, Blaxter 1986) and clearance rate experiments in moderately turbulent water (Kiørboe \& Munk 1986, MacKenzie \& Kiørboe 1995) have suggested that larvae search a hemispherical volume of water in pursuit of prey. However, detailed video recordings of larval search behaviour in calm water suggest that the search volume is wedge shaped (Browman \& OBrien 1992, von Herbing \& Gallager 2000, Galbraith et al. 2004). Moreover, the difference in volume of the visual fields (e.g. 11.5-fold for $10 \mathrm{~mm}$ cod larvae, Galbraith et al. 2004) affects foraging strat- egy and costs; for larvae with wedge-shaped search volumes, successful predation strategies would require a combination of foraging in higher concentrations of prey, switching to larger prey, longer search periods and higher growth efficiency than if search volumes are 11.5-fold larger. The differences in search-volume geometry and size may also influence estimates of how turbulence affects larval feeding rates (Lewis \& Bala 2006), although the functional relationship between turbulence intensity, $E$ and pursuit success has not yet been investigated for wedge searching predators (Table 1). We therefore use our models to demonstrate their general applicability to larval fish ecology and in particular to explore how assumptions of larval searchvolume geometry affect estimates of the role of turbulence on larval fish feeding.

\section{METHODS}

Our model framework consists of 2 integrated modules: (1) the flow field and its turbulence characteristics; and (2) the individual-based larval fish feeding component (which consists of feeding and swimming behaviours of a virtual larva based on experimentally 
derived traits) and a prey field (which, for simplicity, is a field of uniform-sized non-swimming prey particles). Both the larva and prey positions are influenced by the turbulence in the flow field and their locations change over time relative to each other.

Flow field. In the hypothesis that the flow at individual scales is isotropic (Gargett 1989), a simplified but realistic representation of the turbulent flow field can be obtained by using a sum of unsteady random Fourier modes: a so-called kinematic simulation of the flow. This technique was proposed by Kraichnan (1970) and modified versions have been widely used to study physical phenomena. More recently, it has also been applied to analyze plankton interactions (Lewis \& Pedley 2000, 2001, Lewis 2003, Visser \& Jackson 2004, Yamazaki et al. 2004, Mariani et al. 2005, in press).

The turbulent velocity field at a point $\mathbf{x}$ at time $t$ $\mathbf{u}(\mathbf{x}, t)$, is represented as a truncated Fourier series:

$$
\mathbf{u}(\mathbf{x}, t)=\sum_{n=1}^{N}\left(\mathbf{c}_{n} \times \hat{\mathbf{k}}_{n}\right) \exp \left[i\left(\mathbf{k}_{n} \cdot \mathbf{x}+\omega_{n} t\right)\right]
$$

where $N$ modes are selected independently, with randomly directed wave vectors $\mathbf{k}_{n}=\hat{\mathbf{k}}_{n} \boldsymbol{k}_{n}$ and angular frequency $\omega_{\mathrm{n}}$. The Fourier coefficients in the form $\left(\mathbf{c}_{\boldsymbol{n}} \times\right.$ $\hat{\mathbf{k}}_{n}$ ) ensure that the velocity field is incompressible. The amplitude vectors $\mathbf{c}_{\boldsymbol{n}}$ are chosen with amplitude given by:

$$
\left|\mathbf{c}_{\boldsymbol{n}}\right|^{2}=2 \Pi\left(k_{n}\right) \delta k_{n}
$$

and follow an inertial Kolmogorov energy spectrum:

$$
\Pi(k)=\Pi_{0} k^{-5 / 3}
$$

although other spectral shapes can also be used (Fung \& Vassilicos 1998, Malik \& Vassilicos 1999, Lewis \& Pedley 2001). Here $\delta k_{n}=\left(k_{n+1}-k_{n-1}\right) / 2$ for $n$ $=2, \ldots, N-1$, while on the boundaries, $\delta k_{1}=\left(k_{2}-\right.$ $\left.k_{1}\right) / 2$ and $\delta k_{N}=\left(k_{N}-k_{N-1}\right) / 2 . N$ discrete wave numbers are chosen to lie between the inverse of the integral scale, $k_{1}=I^{-1}$, and the inverse Kolmogorov scale, $k_{N}=\eta^{-1}$. Hence, in physical space, this is equivalent to setting the inertial sub-range to lie between $2 \pi I$ and $2 \pi \eta$. Outside this range inertial kinetic energy is set to zero. This does not mean that turbulence-induced relative motion is zero at scales

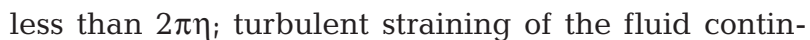
ues all the way down to molecular scales. To avoid harmonic effects (Visser \& Jackson 2004), discrete wave numbers are distributed in a geometric series within the inertial range:

$$
k_{n}=\frac{1}{I}\left(\frac{I}{\eta}\right)^{\frac{n-1}{N-1}}
$$

The angular frequency $\omega_{n}$ is:

$$
\omega_{n}=0.4 \sqrt{k_{n}^{3} \Pi\left(k_{n}\right)}
$$

where the unsteadiness parameter is 0.4 (Malik \& Vassilicos 1999, Visser \& Jackson 2004). Finally, by choosing $\Pi_{0}=1.5 \varepsilon^{2 / 3}\left[1-(\eta / I)^{4 / 3}\right]^{-1}$ in Eq. (3), the appropriate relation between $\varepsilon$ (dissipation rate) and $\Pi(k)$ is ensured (Tennekes \& Lumley 1972).

By construction, the Eulerian 2-point spatial correlation function of velocities has the Kolmogorov form. However, the simulations do not represent the dynamical processes in turbulence, which affects higher order statistics such as intermittency. Consequently, the simulated turbulence will differ from hydrodynamic turbulence, since higher order Eulerian statistics will be Gaussian distributed (Fung et al. 1992, Reynolds 1995, Yamazaki et al. 2004). However the results of Fung et al. (1992) suggested that the detailed aspects of the flow are not so important when modelling many aspects of dispersion; these discrepancies are not likely to substantially influence the results presented here because we are mainly concerned with the small-scale 2-point velocity correlations.

Individual-based model. Neutrally buoyant point particles are used to simulate predators and prey. Each individual moves according to simple species-specific internal rules. The instantaneous swimming velocity of predator particles is the sum of the larval swimming and the local flow velocity, while the prey is assumed to passively drift in the turbulent flow field.

The predator's stochastic swimming motion is obtained by computing the cumulative distribution functions of observed larval behaviour (see below) and then randomly picking numerical values to determine the pause or move behavioural event with its duration, the horizontal turn angle and the swimming velocity.

Feeding processes in the model have been divided into 3 behavioural events: encounter, pursuit and capture (Fig. 1). The biological components for the model are based on laboratory studies conducted at 6 to $8^{\circ} \mathrm{C}$ (MacKenzie \& Kiørboe 2000, Galbraith et al. 2004).

Encounter: We model cod larvae as a pause-travel searcher. This behaviour assumes that cod larvae only
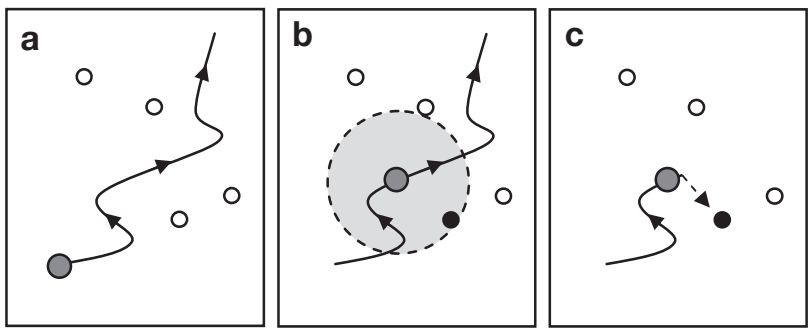

Fig. 1. Processes included in the individual-based model. (a) Each predator moves according to its individual behavior; (b) at each time step during the pause period, it evaluates the number of contacts; (c) if it finds a prey $(\bullet)$, the predator moves towards it until the prey is captured or the contact is lost 
search for prey while pausing between swim events. Although this is likely an oversimplification of larval cod search behaviour (von Herbing \& Gallager 2000, Lewis \& Bala 2006), there is some experimental evidence which demonstrates that cod and other species of fish larvae do search for prey while pausing (MacKenzie \& Kiørboe 1995, von Herbing \& Gallager 2000, Galbraith et al. 2004). The duration and frequency of pause and move events were drawn from literature (Galbraith et al. 2004, and see details below). The distance moved during individual swim events is a combination of the swim speed and duration. If the distance moved is sufficiently large (and assuming no turbulence to advect prey into the search volume), the larva will search a volume of water which has not been searched in the previous pause. However, if the move distance is short, search volumes will partly overlap. The volume of the overlap between successive pauses will depend on search-volume geometry (Galbraith et al. 2004, Lewis \& Bala 2006); we use our models to investigate how different levels of turbulence affect the volume of overlap, and subsequently $E$, for 2 search geometries.

An encounter is recorded by the model if prey are located in the predator's search volume during a pause event. Encounters can occur when larvae move to a location which has a prey in the new search volume, or when a prey is advected by turbulence into the search volume during a pause. Once an encounter occurs, the larva is programmed to begin pursuit; hence, additional prey that could be advected by turbulence into the larval search volume are ignored by the larva. This behaviour is reasonable, because the concentrations of those prey that dominate larval cod diets in the sea (nauplii and copepodites of Pseudocalanus sp. and Calanus finmarchicus, Heath \& Lough 2007) are usually so low (e.g. 1 to $10 \mathrm{l}^{-1}$ ) that it is unlikely that 2 prey would co-occur in volumes of water comparable to a larval search volume (largest volume $\sim 2 \mathrm{~cm}^{3}$ ).

During pauses, the larva scans the surrounding water using the given search-volume geometry. We used 2 search-volume geometries to simulate prey encounter: hemispherical and wedge shaped. The former is defined using a perception radius $(R)$ and horizontal and vertical half angle equal to $90^{\circ}$, while the latter is a function of $R$, the horizontal half-angle $\theta_{\mathrm{h}}=$ $45^{\circ}$ and a vertical half-angle $\theta_{\mathrm{V}}=10^{\circ}$ (Galbraith et al. 2004; our Fig. 2). During pause events the predator's sight direction is kept constant and oriented according to the swimming direction of the last swimming event. Therefore the predator looks along its line of sight while pausing and scans the water in its perception field with no heading changes until the next swimming event.

In general, prey is encountered by the larva when the separation distance between larva and prey is
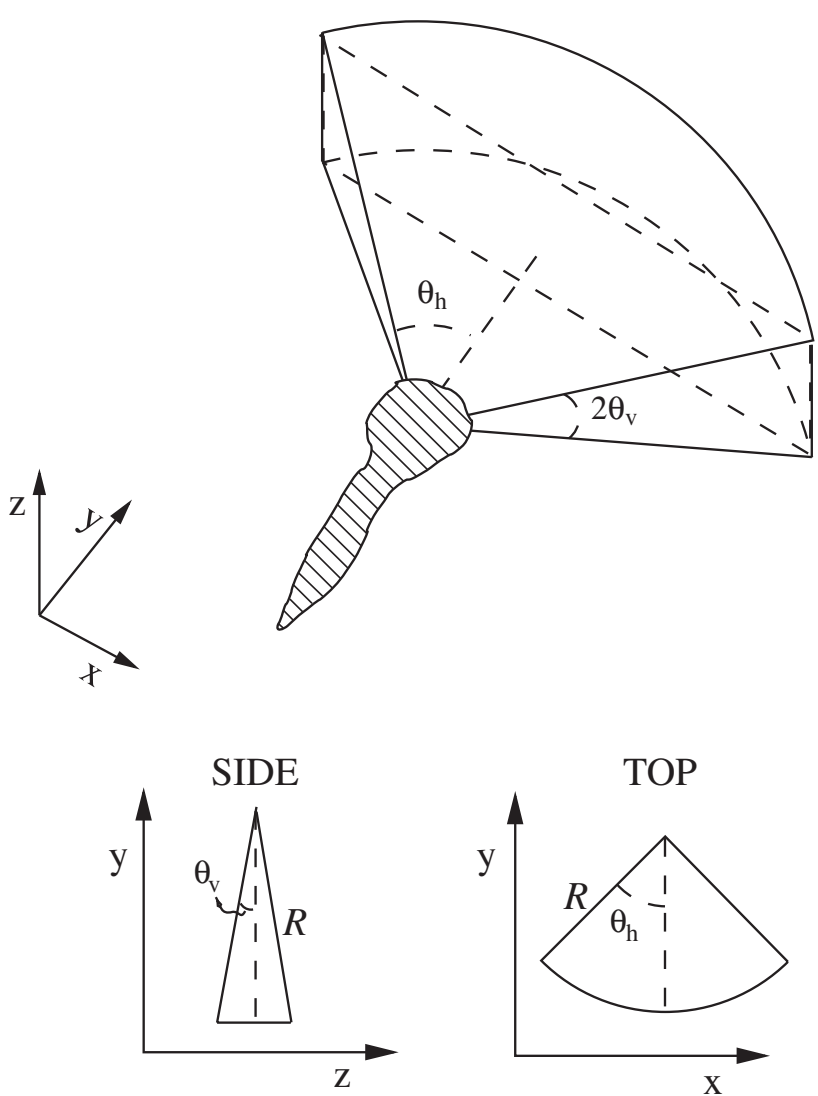

Fig. 2. Wedge-shape geometry of individual predator. $R$ : perception radius; $\theta_{\mathrm{h}}$ : horizontal half angle $\left(45^{\circ}\right) ; \theta_{\mathrm{v}}$ : vertical half angle $\left(10^{\circ}\right)$

lower than the perception radius and the prey is within the visual field of the predator (i.e. when the angle between the axis of the larva's search-volume geometry and the vector connecting predator and prey is lower than the corresponding angle given above).

Pursuit: If the predator finds a prey, it starts to pursue the prey by moving toward it with a given pursuit velocity $\left(V_{\mathrm{P}}\right)$. This prey-tracking behaviour continues until an attack is executed or the prey is lost from view. If more than 1 prey is in the search volume, the predator chooses at random one of these prey as its target. During the pursuit, both predator and prey are affected by the flow field, which modifies the relative positions of the particles. If the predator loses visual contact with the prey it was hunting, the predator resumes its normal swimming behaviour and the pursuit is recorded as a failed pursuit event. Persuit success is derived as the ratio between the numbers of captures and pursuit events.

Capture: Predator pursuit behaviour continues until contact is lost or the prey is captured. Capture is assumed to occur after the predator has approached the prey close enough to enable final attack, i.e. forward thrusting and opening of the mouth. Modelled 
attack success against pursued and fixated prey by cod larvae is high and independent of a wide range of turbulence levels; this is because direct observations (MacKenzie \& Kiørboe 2000) and theory (Fiksen \& MacKenzie 2002) indicate that cod larvae usually approach their prey slowly enough to avoid eliciting escape behaviour of their prey. We therefore assume that when prey-larval separation distance is smaller than a given capture distance $\left(R_{\mathrm{C}}\right)$, prey is successfully attacked and captured. Once the prey is captured, the prey particle is removed from the modelled prey population and the predator resumes its normal search behaviour. Then a new prey is created at a random location in the model domain outside the predator search volume to ensure a constant prey concentration.

Model setup. We analyzed 3 size classes of cod larvae with body dry weights equal to 40,100 and $210 \mu$ g; these weights correspond to larval lengths $(L)$ of 5,6 and $10 \mathrm{~mm}$ based on weight-length relationships for larvae growing in large mesocosms at $8^{\circ} \mathrm{C}$ in nonlimiting food concentrations (Otterlei et al. 1999). Swimming speed, contact radius, $V_{\mathrm{P}}$ and $R_{\mathrm{C}}$ vary according to these larval sizes (Table 2).

Predator swimming behaviour is introduced using the frequency distributions of lengths and durations of moves, swim speed, and turn angles (vertical and horizontal) of a $28 \mathrm{~d}$ old larvae reported in Galbraith et al. (2004), which corresponds to the largest $L(10 \mathrm{~mm})$ used in the present study (Otterlei et al. 1999). We assume that the same frequency distributions apply for the 2 other larval size classes, and that the swim speed changes according to a cod-specific functional relationship between swimming speed and body length for larvae and juveniles at $8^{\circ} \mathrm{C}$ (Peck et al. 2006). We used average swim speeds $(u)$ of 1.1 and $0.8 \mathrm{~mm} \mathrm{~s}^{-1}$ for $L=6$ and $=5 \mathrm{~mm}$, respectively; the variability of swimming speed for each size group was based on $u$ for $L=$ $10 \mathrm{~mm}\left(u=5.4 \mathrm{~mm} \mathrm{~s}^{-1}\right)$ and its frequency distribution (Galbraith et al. 2004), and scaled downward for the smaller sizes (Fig. 3). As a result of this scaling procedure, larvae with slower $u$ have less variability in swim speed.

Table 2. Fish larvae size classes used in the present study. $V_{\mathrm{P}}$ : pursuit velocity; $R_{\mathrm{C}}$ : capture distance. Data sources are also shown

\begin{tabular}{|lcccccc|}
\hline $\begin{array}{l}\text { Weight } \\
(\mu \mathrm{g})\end{array}$ & $\begin{array}{c}\text { Length } \\
(\mathrm{mm})\end{array}$ & $\begin{array}{c}\text { Age } \\
(\mathrm{d})\end{array}$ & $\begin{array}{c}\text { Mean speed } \\
\left(\mathrm{mm} \mathrm{s}^{-1}\right)\end{array}$ & $\begin{array}{c}\text { Radius } \\
(\mathrm{mm})\end{array}$ & $\begin{array}{c}V_{\mathrm{P}} \\
\left(\mathrm{mm} \mathrm{s}^{-1}\right)\end{array}$ & $\begin{array}{c}R_{\mathrm{C}} \\
(\mathrm{mm})\end{array}$ \\
\hline $40^{\mathrm{a}}$ & $5^{\mathrm{a}}$ & $8^{\mathrm{a}}$ & $1.3^{\mathrm{c}}$ & $5^{\mathrm{d}}$ & $0.8 \pm 0.1^{\mathrm{e}}$ & $1.0 \pm 0.1^{\mathrm{d}}$ \\
$100^{\mathrm{a}}$ & $6^{\mathrm{a}}$ & $19^{\mathrm{a}}$ & $2.2^{\mathrm{c}}$ & $6^{\mathrm{d}}$ & $1.1 \pm 0.1^{\mathrm{e}}$ & $1.2 \pm 0.1^{\mathrm{d}}$ \\
$210^{\mathrm{a}}$ & $10^{\mathrm{a}}$ & $28^{\mathrm{b}}$ & $5.4^{\mathrm{b}}$ & $10^{\mathrm{b}}$ & $2.6 \pm 0.3^{\mathrm{e}}$ & $2.0 \pm 0.2^{\mathrm{d}}$ \\
${ }^{\mathrm{a}}$ Otterlei et al. (1999); ${ }^{\mathrm{b}}$ Galbraith et al. (2004); ${ }^{\mathrm{c}}$ Peck et al. $(2006) ;$ \\
${ }^{\mathrm{d}}$ MacKenzie \& Kiørboe (2000); ${ }^{\mathrm{e}}$ Werner et al. (2001)
\end{tabular}

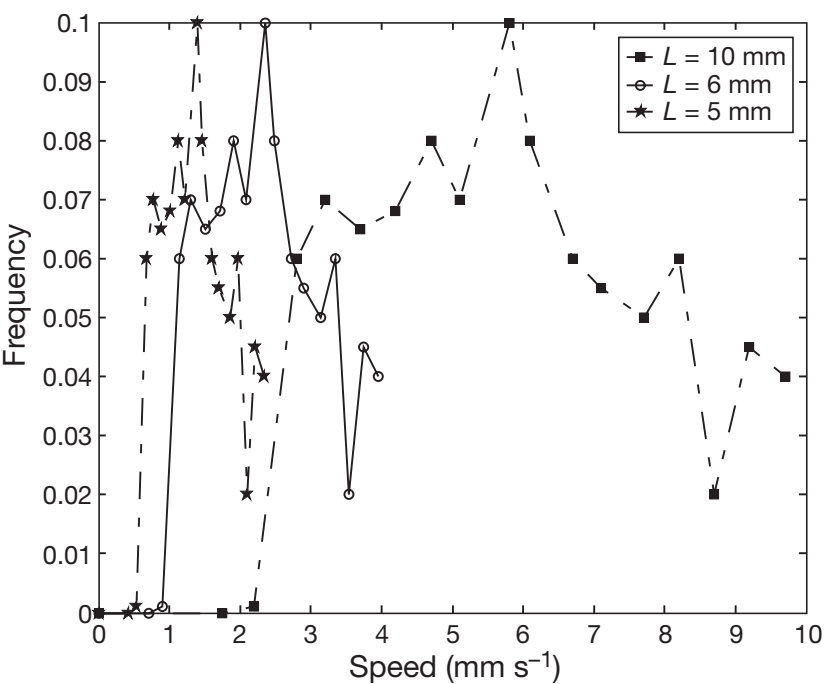

Fig. 3. Swimming speed frequency distributions of the 3 size classes considered in the model. For the largest class $(L=$ $10 \mathrm{~mm}$ ) we used data reported in Galbraith et al. (2004), while in the other 2 classes ( $L=6$ and $5 \mathrm{~mm}$ ) we scaled the distribution to fit their average swimming speed

$R$ is assumed to be equal to $L$ and $R_{\mathrm{C}}$ is assumed to be $20 \%$ of this value (MacKenzie \& Kiørboe 2000). $V_{\mathrm{P}}$ has been estimated by dividing $R$ by the pursuit time $\left(t_{\mathrm{p}}\right) \cdot t_{\mathrm{p}}$ for cod larvae of different sizes is assumed to be a function of body length, as determined empirically from laboratory observations of several species of larval fish (Werner et al. 2001):

$$
t_{\mathrm{P}}=3.9(L / 10)^{-0.6}
$$

The larval body lengths, weight and age, together with the resulting $u, R, R_{\mathrm{C}}$ and $V_{\mathrm{P}}$ are reported in Table 2 . We assumed $10 \%$ variation in mean values of $R_{\mathrm{C}}$ and $V_{\mathrm{P}}$.

We used 10000 passive moving prey particles and a single predator swimming in a numerical cubic box of $1 \mathrm{~m}^{3}$ in volume. The prey concentration we used $\left(10 \mathrm{l}^{-1}\right)$ is comparable to concentrations of nauplii and copepodites that are found in many areas where fish larvae feed and grow (MacKenzie et al. 1990).

We analyzed larval feeding processes at 9 different turbulence levels $\left(\varepsilon=10^{-9}\right.$ to $10^{-4} \mathrm{~m}^{2} \mathrm{~s}^{-3}$ ) and in calm water. This range encompasses turbulence typical of natural systems, from the deep ocean interior up to strong tidal and wind-mixed regimes (Peters \& Marrasé 2000, Thorpe 2004). Kinematic simulations have been used with 32 Fourier modes and $I=0.5 \mathrm{~m}$ (i.e. integral length scale is $3.6 \mathrm{~m}$, Table 3 ).

The integration of the trajectories is performed with a time step of $0.1 \mathrm{~s}$. Such a short time step is required to prevent a 
Table 3. Dissipation rate $(\varepsilon), 2 \pi$ Kolmogorov length scale $(2 \pi \eta)$, rms turbulence velocity scale $(W)$ and Reynolds number $\left(\operatorname{Re}_{\lambda}\right)$ of the kinematic simulations for kinematic viscosity $\varepsilon v=10^{-6} \mathrm{~m}^{2} \mathrm{~s}^{-1}$, integral length scale $3.6 \mathrm{~m}(I=0.5 \mathrm{~m})$ and 32 Fourier modes

\begin{tabular}{|lrrr|}
\hline $\begin{array}{l}\varepsilon \\
\left(\times 10^{-6} \mathrm{~m}^{2} \mathrm{~s}^{-3}\right)\end{array}$ & $\begin{array}{c}2 \pi \eta \\
(\mathrm{mm})\end{array}$ & $\begin{array}{c}W \\
\left(\mathrm{~mm} \mathrm{~s}^{-1}\right)\end{array}$ & $\mathrm{Re}_{\lambda}$ \\
\hline 0.001 & 35.3 & 0.8 & 77.2 \\
0.01 & 19.9 & 1.7 & 113.2 \\
0.05 & 13.3 & 2.9 & 148.1 \\
0.1 & 11.2 & 3.7 & 166.2 \\
0.5 & 7.5 & 6.3 & 217.4 \\
1 & 6.3 & 7.9 & 244.0 \\
5 & 4.2 & 13.6 & 319.0 \\
10 & 3.5 & 17.1 & 358.1 \\
100 & 2.0 & 36.8 & 525.6 \\
\hline
\end{tabular}

predator from missing any prey that might be passing through its contact area between time steps, and also because swim and pause events are short (MacKenzie \& Kiørboe 1995, von Herbing \& Gallager 2000, Galbraith et al. 2004). Numerical tests showed that when using this time step, there is no real difference between the results obtained integrating in time with a fourth-order Runge-Kutta method and those obtained with a first-order Euler scheme. Therefore, the much faster Euler integration scheme was used in all simulations to reduce computing time.

In order to maintain the initial concentration in the numerical box, when particles reach the boundary of the box they are reinserted in the domain using pseudo-periodic boundary conditions (Mariani et al. 2005). A particle that leaves one of the sides of the domain is repositioned at random on the opposite side, with the condition that the direction of the velocity at the point is directed towards the interior of the domain.

To test the ability of the kinematic simulations to realistically represent ocean turbulence at scales relevant to larval fish feeding, we ran the model at different turbulence levels using 100 equally spaced passive particles. We then derived the particle-particle velocity difference and separation distance. According to well known theories of turbulent energy dissipation (Tennekes \& Lumley 1972, Rothschild \& Osborn 1988), relative velocity scales with separation distance according to $w=1.8(\varepsilon s)^{1 / 3}$, where the relative velocity $(w)$ is a function of $\varepsilon$ and the separation distance $(s)$.

The distribution of relative velocities between particles showed a wide range of values. We calculated mean velocities for a uniform range of bins of logarithmically spaced $s$. This averaging procedure is similar to that used for binning small-scale velocity shear and $\varepsilon$ data obtained in the sea with shear micro-structure profilers (Oakey \& Elliott 1982, Simpson et al. 1996).
The resulting average velocity as a function of $s$ at 2 turbulence levels $\left(\varepsilon=10^{-8}\right.$ and $\left.10^{-6} \mathrm{~m}^{2} \mathrm{~s}^{-3}\right)$ was then plotted and compared with the theoretical values (see Fig. 4a).

Model execution and outputs. Our model approach incorporates randomization and stochasticity in many of its parameterisations (e.g. swimming behaviour, turbulence flow fields). We executed the model 5 times per dissipation rate (9 levels + calm water) for each of 3 larval size groups for each of the 2 search-volume geometries (i.e. a total of $5 \times 10 \times 3 \times 2=300$ simulations); each simulation was executed by initiating the run using a different random number sequence. Feeding output data are shown as means of the 5 runs for each combination of larval size and search-volume geometry. Because we used realistic concentrations of prey $\left(10\right.$ prey $\left.^{-1}\right)$ in our model, each simulation was allowed to run $4 \mathrm{~h}$ (hemisphere) or $12 \mathrm{~h}$ (wedge) to enable sufficient encounters and captures for meaningful interpretation. We derive the following biological outputs from the model: $E$ (prey $\mathrm{h}^{-1}$ ), pursuit success and ingestion enhancement factor $(\psi)$ defined as:

$$
\psi=\frac{\beta_{\mathrm{T}}-\beta_{\mathrm{C}}}{\beta_{\mathrm{C}}}
$$

where $\beta_{\mathrm{C}}$ and $\beta_{\mathrm{T}}$ are the clearance rates derived from the number of captures under calm and turbulent conditions, respectively.

Encounter, pursuit and capture can be illustrated visually in virtual format by reconstructing the predator-prey interactions and the associated trajectories. The simulated feeding processes can be viewed in Video clips 1 to 4 (Video clips 1 \& 2: calm water conditions; Video clips 3 \& 4: turbulent water conditions), available as MEPS Supplementary Material online at www.int-res.com/articles/suppl/m347p155_videos/.

The model is developed in C++ with an entirely objectoriented programming approach. Each of the 300 simulations using the model setup as described here and with turbulence, typically required $1 \mathrm{~h}$ on a 64 -bit Intel ${ }^{\circledR}$ Xeon 3.2Ghz processor and $2 \mathrm{Mb}$ cache size.

Validation of model outputs with observations. We conducted 3 sets of comparisons of our modelling results with independently derived feeding and growth data. We first compared our model outputs with literature observations of cod larvae feeding behaviour in calm and turbulent water. As no direct observations of $E$ or pursuit success are yet available for wild cod (or any other) larvae growing in the sea, we used 2 different sets of laboratory data $(E$, pursuit success) for this comparison. The laboratory observations of $E$ (MacKenzie \& Kiørboe 1995) and pursuit behaviour (MacKenzie \& Kiørboe 2000) in different levels of quantified turbulence were compared with the model outputs derived using wedge and hemi- 
spherical search volumes. The sizes of larvae used in the laboratory experiments were similar to those used in the present modelling study.

The third comparison involved ingestion rates derived from our model and ingestion rates estimated for cod larvae growing in nature. We extracted field estimates of larval cod growth rate data from a detailed literature case study and estimated ingestion rates and food requirements, given reasonable assumptions of growth efficiencies and prey sizes and concentrations. Further details of the comparison are given in 'Results.' This comparison enabled us to estimate which searchvolume geometry could satisfy observed feeding rates in the wild, and how prey size and concentration could interact with search volume geometry to affect larval feeding and growth rates.

\section{RESULTS}

\section{Turbulence}

The relative velocities as derived from the kinematic simulation at 2 turbulence levels $\left(\varepsilon=10^{-8}\right.$ and $10^{-6} \mathrm{~m}^{2}$ $\mathrm{s}^{-3}$ ) reproduce the main features and patterns of the turbulence flow field (i.e. turbulence velocity and the overall structure of the flow field) at scales relevant to encounter and pursuit (Fig. 4a). As an illustration of those processes, we show in Fig. 4b a typical velocity field with the trajectories of a hundred drifting particles. The flow field is an instantaneous 2-dimensional snapshot extracted from a 3-dimensional kinematic simulation at $\varepsilon=10^{-7} \mathrm{~m}^{2} \mathrm{~s}^{-3}$. Particles were initially released $1 \mathrm{~cm}$ apart and they show the streamlines of the turbulence field, where areas of convergence and divergence are both present along their paths. Also shown is the presence of a small eddy within the turbulence flow field with size comparable to the predator perception distance (Fig. $4 \mathrm{~b}$ at $x \approx 0.8, y \approx 0.7 \mathrm{~cm}$ ).

\section{Feeding processes}

$E$ increased as dissipation rates increased for both search geometries (Fig. 5a-c). $E$ for larvae using the wedge-shaped search volumes are lower than for those using the hemisphere in all 3 size classes; 10, 6 and $5 \mathrm{~mm}$ larvae using hemisphere search volumes encountered, on average, 8-, 6- and 5-fold more prey, respectively, than larvae using wedge-shaped search volumes (Fig. 5a-C).

The different search-volume geometries show different sensitivities to the influence of turbulence. Maximum $E$ for larvae using the hemisphere search-volume geometry increased ca. 10-, 7- and 5-fold for 5, 6 and
$10 \mathrm{~mm}$ larvae, respectively (Fig. $5 \mathrm{a}-\mathrm{c}$ ). $E$ for the wedge shape increased ca. 11-, 8.5- and 7-fold for the 3 size classes (Fig. 5a-c).

The average relationship between $E$ and turbulence using all the geometries and size classes is $E \sim \varepsilon^{1 / 6}$. The
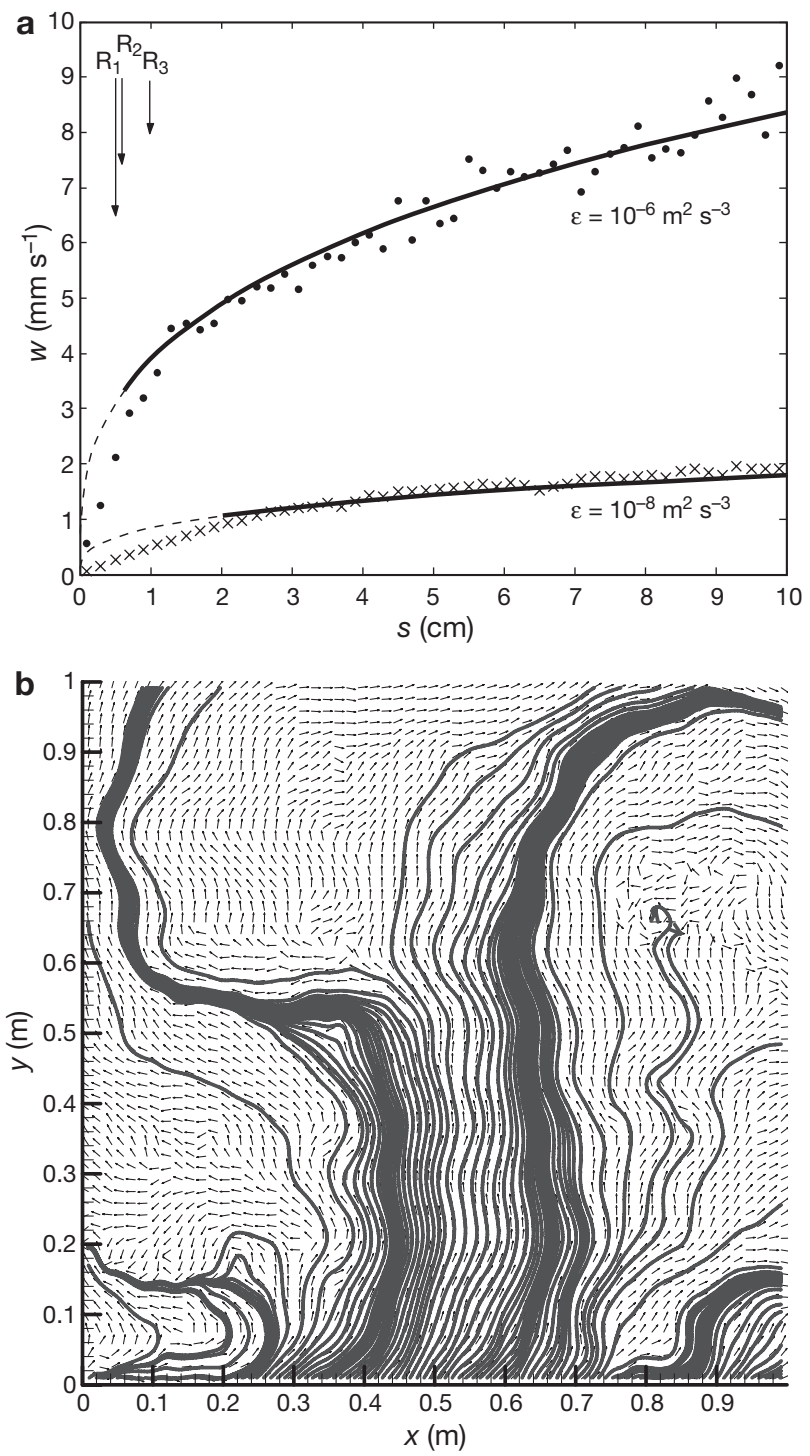

Fig. 4. (a) Structure function between particle-particle separation distance $(s)$ and relative velocity between particles $(w)$ for 2 different turbulent dissipation rates. Distances and velocities were derived by releasing 100 particles in the synthetic turbulent field (see 'Methods' for details). Average relative velocities at each separation distance were then compared with the theoretical structure function in the inertial range, i.e. solid lines, $w=1.8(\varepsilon s)^{1 / 3}$. Note at small scales (top line: $6 \mathrm{~mm}$; lower line: $\sim 20 \mathrm{~mm}$ ) the transition to a viscous dominated flow. $\bullet$ high turbulence $\left(\varepsilon=10^{-6} \mathrm{~m}^{2} \mathrm{~s}^{-3}\right), \times$ : low turbulence $\left(\varepsilon=10^{-8} \mathrm{~m}^{2}\right.$ $\mathrm{s}^{-3}$ ). Arrows indicate the values of the reactive distances used in this work $\left(\mathrm{R}_{1}=5 \mathrm{~mm} ; \mathrm{R}_{2}=6 \mathrm{~mm} ; \mathrm{R}_{3}=10 \mathrm{~mm}\right)$. (b) Representation on a grid of the simulated flow field and trajectories of passive particles as represented by the modelled turbulence. Particles have been released at $y=1 \mathrm{~mm}$ and at equally distant values of $x$ using separation distance of $1 \mathrm{~cm}$ 

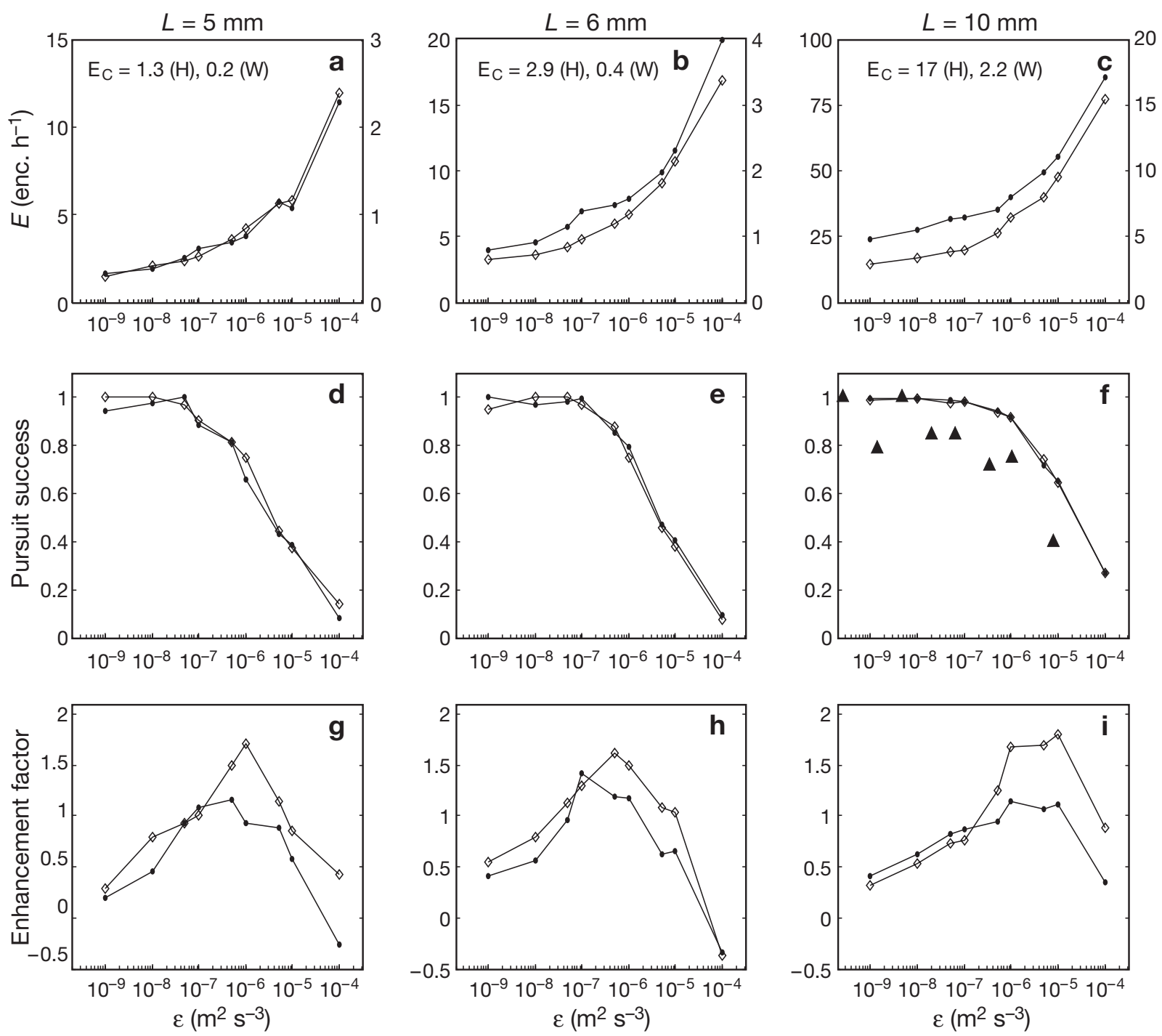

Fig. 5. (a-c) Modelled encounter rate $(E),(d-f)$ pursuit success and $(g-i)$ enhancement factor based on ingested prey, all as a function of dissipation rate $(\varepsilon)$ and cod size $(L=5,6,10 \mathrm{~mm})$. Two search geometries are considered: hemisphere $(\bullet)$ and wedgeshaped $(\diamond)$. The number of encounters in calm water $\left(E_{\mathrm{C}}\right)$ for the hemisphere $(\mathrm{H})$ and wedge $(\mathrm{W})$ are reported in $(\mathrm{a}-\mathrm{C})$. Note $E$ has $2 y$-axes, left and right for the hemisphere and wedge cases, respectively. Observed values of pursuit success ( $\mathbf{\Delta}$, MacKenzie \& Kiørboe 2000) for $10 \mathrm{~mm}$ cod larvae shown in (f) for comparison

resulting proportionality between dissipation and $E$ is therefore lower than theoretical relationships which assume that all intersections of prey with predator search volumes are encounters, i.e. $\sim \varepsilon^{1 / 3}$. The smallest exponent represents the largest larval size class with hemisphere search geometry; the exponent increases among smaller size classes and larvae using the wedge-shaped search geometry. Exponents differ among search volumes and larval sizes because the predator cannot encounter other prey during the pursuit events. An increase in the turbulence level yields more encounters and therefore more pursuits; however, time allocated for pursuit reduces the time available for prey search and encounter.
Pursuit success decreases exponentially with turbulence for both the wedge and the hemisphere search volumes (Fig. 5d-f). The functional relationship to turbulence for the 2 search geometries is nearly identical. Pursuit success was $100 \%$ by larvae during relative low turbulence regimes (0 to $10^{-7} \mathrm{~m}^{2} \mathrm{~s}^{-3}$ ), but further increases in turbulence reduce the success.

The increase in the number of encounters in combination with the reduced pursuit success results in a dome-shaped distribution of the captures and overall ingestion rate (Fig. $5 \mathrm{~g}-\mathrm{i}$ ). The enhancement of ingestion rate with turbulence peaks at between $10^{-6}$ to $10^{-5}$ $\mathrm{m}^{2} \mathrm{~s}^{-3}$ for the largest size, but at lower turbulence levels for smaller sizes of larvae. The dome-shaped relation- 
ship of ingestion to turbulence is evident for both the wedge-shaped and hemisphere search geometries. The magnitude of the enhancement is similar for wedgeshaped and hemisphere geometries at low turbulence levels; however, when turbulence was $>5 \times 10^{-7} \mathrm{~m}^{2} \mathrm{~s}^{-3}$, the enhancement was larger for the wedge-shaped. The relatively higher ingestion rate at intermediate levels of turbulence for the wedge-shaped geometry is due to its greater sensitivity of $E$ to turbulence.

\section{Comparison with observations}

Many of the main results from the model outputs compare favorably with feeding behaviours directly observed and estimated with real cod larvae. We first consider $E$. The model indicates that $6 \mathrm{~mm}$ cod larvae, if assumed to have hemispherical search volumes, encounter 2.9 and 7.0 prey $\mathrm{h}^{-1}$ in calm and turbulent ( $\varepsilon=10^{-7} \mathrm{~m}^{2} \mathrm{~s}^{-3}$ ) water, respectively, at a prey concentration of $10 \mathrm{l}^{-1}$. These $E$ values are similar to those observed directly by MacKenzie \& Kiørboe (1995): 3 and 10 encounters $\mathrm{h}^{-1}$ for cod larvae $(L=5.2 \mathrm{~mm})$ in calm and turbulent $\left(\varepsilon=7.4 \times 10^{-8} \mathrm{~m}^{2} \mathrm{~s}^{-3}\right)$ water, respectively, at the same prey concentration. If wedgeshaped search geometry is applied in the model, estimated $E$ is around 6-fold smaller than that observed.

The model predicts that pursuit success declines nonlinearly as a function of $\varepsilon$, regardless of which of the 2 search volumes are assumed (Fig. $5 d-f$ ). The form of the modelled pursuit success is similar to the relationship between pursuit success and turbulence directly observed for cod larvae in several turbulence treatments in laboratory experiments described by MacKenzie \& Kiørboe (2000). They found an inverse exponential relationship between the probability of a successful pursuit and the turbulent velocity consistent with the modelled relationships derived here (Fig. 5f). They also observed that pursuit success was higher at a given turbulence level among larger (12.3 mm) larvae than smaller $(8.7 \mathrm{~mm})$ larvae. This pattern is also evident in our new model calculations (Fig. 5d-f).

The third comparison uses field-estimated growth rates. Growth rates of cod larvae, for example on Georges Bank, can reach $14 \%$ body weight $\mathrm{d}^{-1}$ at a temperature of 7 to $8^{\circ} \mathrm{C}$ (Buckley et al. 2004, Lough et al. 2005, Buckley \& Durbin 2007); growth rates at similar temperatures (provided that food supplies are nonlimiting) can be higher in areas where longer photoperiod allows more search time per day (Otterlei et al. 1999, Helle 2000). Assuming $33 \%$ growth efficiency for converting ingested prey to body tissue (a typical value for many larval fish species; Houde 1989, MacKenzie et al. 1990), the number of ingested prey as a function of weight-specific growth rate can be derived if prey weights are known. Diets of early stages of larval cod in most areas of their distribution are dominated by nauplii of Pseudocalanus spp. and Calanus finmarchicus (Heath \& Lough 2007). We used prey concentrations $\left(2 \mathrm{l}^{-1}\right)$ similar to those observed on Georges Bank and considered 2 prey sizes in our analyses: small, i.e. $0.26 \mu \mathrm{g}$ (Pseudocalanus sp. nauplii, Monteleone \& Peterson 1986) and big, i.e. $1.5 \mu \mathrm{g}$ C (Calanus finmarchicus nauplii, Davis 1984).

The number of prey required to satisfy observed growth rates can therefore be compared with the ingestion estimated by the model for wedge and hemisphere, assuming a daily feeding period equal to $12 \mathrm{~h}$ and that all feeding occurred at the turbulence level which maximized ingestion rates.

The calculations and comparisons show that if larval diets only comprise small prey at $2 \mathrm{l}^{-1}$, they are not able to acquire the daily ration required for a low growth rate $\left(6 \% \mathrm{~d}^{-1}\right)$, regardless of search volume geometry or larval size (Fig. 6a). The discrepancy between required and ingested prey amounts is higher for larvae growing at faster rates (up to $14 \%$, as observed in the field) and decreases as prey concentration increases (Fig. 6b,c). Alternatively, if larvae are able to locate and capture large prey, and if they employ hemisphere search geometry, then all sizes of larvae are able to acquire enough prey to grow at moderate rates (6 to $10 \% \mathrm{~d}^{-1}$ ) at low prey concentration. However, at the same prey concentration, if they have a wedge search geometry, none of the 3 size groups will be able to meet the observed food demand even when ingesting large prey; ingestion rates based on wedge search geometry are ca. $80 \%$ lower.

\section{DISCUSSION}

Our integrated object-oriented numerical modelling approach reproduced many aspects of the complicated process of larval feeding in turbulent environments. We first showed that the turbulence simulation scheme used produces realistic levels of turbulent velocity at scales important for larval fish feeding. Although the model is a simplified description of turbulence, our relationship between the relative velocity of simulated particle-pairs and the separation distances between them was consistent with well-known theories of turbulent motion at small scales (Tennekes \& Lumley 1972) and with experimental evidence based on direct tracking of particles (neutrally buoyant beads, copepods) in turbulent water (Hill et al. 1992, MacKenzie \& Kiørboe 2000). These results assure us that the equations used to estimate the turbulent velocities and dissipation rates in our framework were reliable and that the velocities themselves were reasonable. 

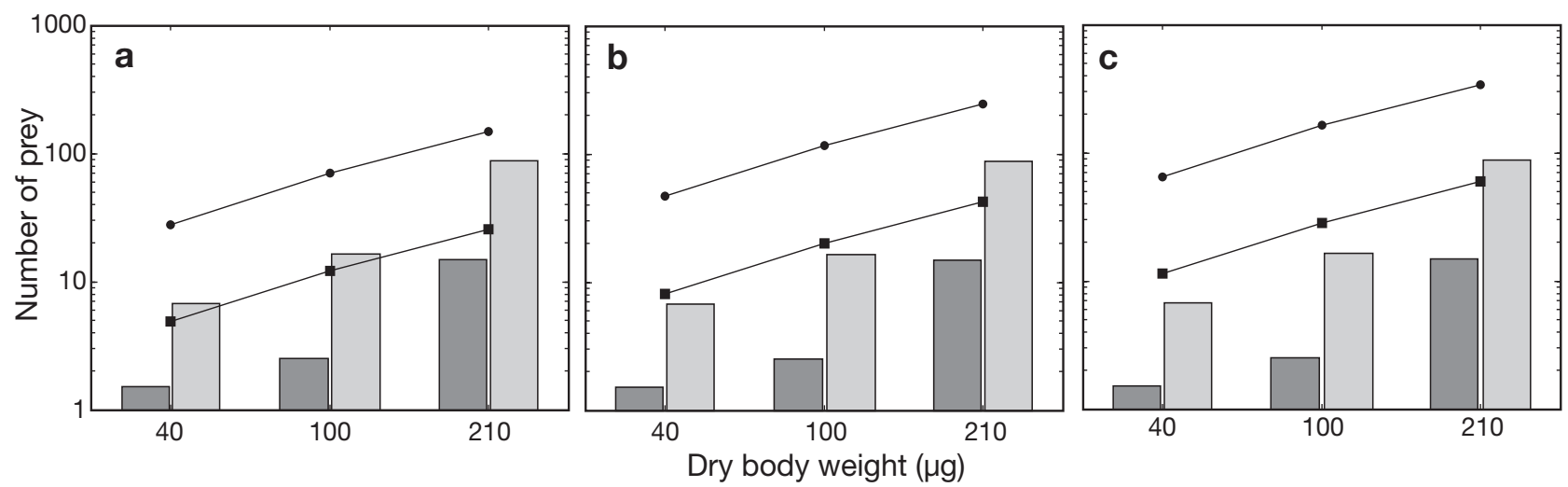

Fig. 6. Larval cod ingestion rates at prey concentration $2 \mathrm{l}^{-1}$. Vertical bars represent model predictions of maximum daily ingestion rate using wedge (dark gray) or hemisphere (light gray) search-volume geometry for 3 size classes (weights shown correspond to $L=5,6,10 \mathrm{~mm}$; Otterlei et al. 1999). Modelled ingestion rates assume feeding occurred at a turbulence level which maximizes ingestion rate and during a $12 \mathrm{~h}$ daily feeding period. Also shown for comparison (lines) is the number of prey ingested by wild cod larvae on Georges Bank growing at 3 different rates ( $\mathrm{a}: \mathrm{g}=6 \% \mathrm{~d}^{-1}, \mathrm{~b}: \mathrm{g}=10 \% \mathrm{~d}^{-1}$; $\mathrm{c}: \mathrm{g}=14 \% \mathrm{~d}^{-1}$; Lough et al. 2005), $33 \%$ growth efficiency and 2 prey sizes (circles: $0.26 \mu \mathrm{g}$ dry weight; squares: $1.5 \mu \mathrm{g}$ dry weight). Note that the $y$-axis is expressed in logarithmic units

The model also produced biological results which are consistent with key features of many previous analytical and experimental studies. In particular, our simulation using hemispherical search volume produced results similar to those in 3 prior analytical models (Matsushita 1992, MacKenzie et al. 1994, Jenkinson 1995): an increase in $E$ with turbulence, a nonlinear decrease of pursuit success as turbulence increases, and the familiar dome-shaped response of capture or ingestion rate to increasing turbulence. Our results from modelling the role of wedge-shaped search geometry across turbulence levels also yielded an exponential decay of pursuit success and a dome-shaped response of ingestion rate to increasing turbulence intensity. Highest ingestion rates with both geometries are predicted to occur in moderately turbulent environments, such as tidally mixed frontal zones where dissipation rates are ca. $10^{-6}$ to $10^{-5} \mathrm{~m}^{2} \mathrm{~s}^{-3}$.

Since we excluded escape responses of prey and possible effects of turbulence on the orientation of predator, the model consistently estimated $100 \%$ pursuit efficiency in low turbulent regimes. Therefore the mechanism associated with the decrease in pursuit success as turbulence increases is the decrease in time for which the encountered prey is within the larval fish search volume (MacKenzie et al. 1994, MacKenzie \& Kiørboe 2000, Lewis \& Bala 2006). These findings, and their consistency with experimental evidence, indicate that the biological component of our model also produced reliable results. The results differ, however, in some details (e.g. pursuit efficiency and level of enhancement of $E$ at particular turbulence levels) because of specific differences in biological assumptions used in the models.
The high pursuit efficiencies at low turbulence levels, including calm water, are consistent with laboratory observations in calm and low turbulent water (MacKenzie \& Kiørboe 2000) using larvae whose sizes were similar to those used in our modeling study. However, we would expect lower pursuit success in both calm and turbulent water for some other combinations of larvae and prey sizes; larval foraging success improves with size and age (Rosenthal \& Hempel 1970, Blaxter 1986, von Herbing \& Gallager 2000), and copepods can detect approaching predators and initiate escape manoeuvres (Visser 2001 Fiksen \& MacKenzie 2002). These size-based interactions can result in lower pursuit and capture successes than those estimated here, and likely are important factors influencing the prey size spectra of larvae captured in the field (e.g. Munk 1992, 1995, Pepin \& Penney 1997). See also 'Future prospects' section below.

\section{Sensitivity to search volume geometry}

Each of the 3 feeding processes we investigated (encounter, pursuit, ingestion) showed similar functional responses to increasing turbulence, regardless of whether a hemisphere or wedge-shaped volume was assumed; $E$ increased exponentially, pursuit success declined nonlinearly and ingestion rate was related in a dome-shaped way to turbulence. Moreover, and as expected, employing a wedge-shaped search volume resulted in substantially lower encounter and ingestion rates than use of a hemispherical search volume. This has implications for estimates of larval feeding rates in nature, and the size composition of 
prey that larvae must locate and consume in order to survive (see 'Influence of search volume geometry on larval feeding in nature' below).

The relative impact of turbulence on ingestion rate was higher when assuming a wedge-shaped search geometry than when assuming a hemispherical geometry. In both instances, the large decrease in pursuit success at increasing turbulence is partly offset by increases in prey encounter.

The difference in sensitivity to turbulence between the search geometries is due to 2 mechanisms, and can be summarized in a simplified model of the processes involved in prey encounter by a pause-travel predator (MacKenzie \& Kiørboe 1995):

$$
E=\frac{(S V-\text { overlap }) \rho_{\mathrm{p}}}{T_{\text {tot }}}+A \rho_{\mathrm{p}} w \frac{T_{\mathrm{p}}}{T_{\text {tot }}}
$$

Here, $E$ is a function of 2 basic processes: what is in the search volume when it pauses, and what enters while it is paused. $S V$ is predator search volume, $\rho_{\mathrm{P}}$ is the prey concentration, $A$ is area of the search space, $W$ is the turbulent velocity, $T_{\mathrm{p}}$ is the time spent pausing (searching) and $T_{\text {tot }}$ is duration of the pause + travel events.

First, it can be shown that the overlap between successive search volumes for a hemispherical searcher is much larger than for a wedge searcher, given experimentally observed movement distances and speeds, and pause durations and frequencies (Galbraith et al. 2004, Lewis \& Bala 2006). Given these behaviours, the larvae do not move to completely unsearched volumes of water when moving to new locations. Consequently, successive search volumes partly overlap each other and the volume of the overlap itself is greater for hemisphere geometry than for wedge geometry. Volume of overlap decreases as turbulence intensity increases. This decrease is due to the turbulent velocity which (when combined with the larva's swim velocity and duration) effectively increases the distance moved by the larva during individual swim events, relative to the distance moved in calm water. Because the volume of a hemisphere is ca. 11-fold larger than the volume of a wedge, the decrease in overlap with increasing turbulence is greater for the hemisphere than for the wedge.

The second reason the search geometries have different sensitivities to turbulence is the difference in surface-area-to-volume ratios between the 2 shapes. Switching from a hemispherical to a wedge-shaped search space leads to a ca. 11-fold reduction of the volume of the search space, but only a ca. 5 -fold reduction in the surface area exposed to the turbulent flux of prey into the search volume. Hence the greater surface area-volume ratio of wedges compared to hemispheres means that turbulence (relative to the calm situation) will have a greater influence on $E$ of wedge-shaped search geometries. Qualitatively, these surface areavolume considerations are represented by the ratio of the 2 terms in Eq. (8), ( $V-$ overlap) $/\left(A w T_{p}\right)$. Some earlier analyses have excluded the role of turbulence on advection of prey into the search volume (Galbraith et al. 2004); consequently, when using the wedge, the influence of turbulence on larva encounter and net energy gain was underestimated.

\section{Development of modelling approaches}

Our study extends the work of some earlier modelling investigations into the role of turbulence on feeding in larval fish (Table 1) to include several combinations of search-volume geometry (hemisphere, wedge), turbulence level (calm to storm/tidal front levels) and predatory components (encounter, pursuit). We believe that the numerical, individual-based approach has many benefits because the $E$ and pursuit success of individual larvae can be followed and recorded over time, and because complex behaviours can be relatively easily incorporated into the modelling framework. This flexibility could be useful, for example, when simulating larvae of different sizes preying on a zooplankton community composed of prey having different sizes and escape behaviours.

The modelling approach we have used includes many assumptions about larval search behaviour and search geometry. In particular, we have assumed that cod larvae are pause-travel searchers. However, cod larvae also perceive prey while gliding and swimming (von Herbing \& Gallager 2000, MacKenzie \& Kiørboe 2000) and can encounter prey as they are being advected towards them (MacKenzie \& Kiørboe 2000). For example, we have observed cod larvae in our laboratory studies which use their body posture and fin positions to hover so they remain oriented against small scale flow structures associated with turbulence (see Video clip 5 in MEPS Supplementary Material online at www.int-res.com/articles/suppl/m347p155_ videos/). The flow carries prey towards the larva, and if sufficiently slow, enables capture of the advecting prey. Hovering behaviour has been observed in some other fish species occupying habitats with flow (McLaughlin et al. 2000).

In these situations, the larvae display search behaviour similar to a cruise predator, where $E$ depends on relative velocities between prey and predator (Gerritsen \& Strickler 1977, Rothschild \& Osborn 1988). Adopting a strategy of reduced or no swimming in turbulent water has been suggested in the literature (Sundby \& Fossum 1990, Dower et al. 1997, MacKenzie 2000), has been observed in the laboratory (Munk \& Kiørboe 1985, Munk 1992, 1995, MacKenzie \& Kiørboe 
2000), and has theoretical bioenergetic benefits (Lewis \& Bala 2006). This behaviour is common among juvenile and larger sizes of fish, particularly among those inhabiting streams (McLaughlin et al. 2000) and near coral reefs (Hamner et al. 1988), and may be a behaviour that develops rapidly during larval ontogeny. We hypothesise that it is also common among larvae in turbulent environments of open and coastal seas, and technologies and methodologies now exist for testing this and other feeding-related hypotheses (MacKenzie 2000). Larval search behaviour may at times therefore be pause-travel, while at others it may more closely resemble cruise or sit-wait behaviour, depending on factors such as prey concentration, larval hunger level and turbulence intensity (see also von Herbing \& Gallager 2000).

Our modelling approach employs a turbulence routine which allows all prey to be advected by the smallscale motion of the turbulence. As a result, some prey can be advected into the search volumes of larval fish predators, and the separation distances and relative velocities of the prey to each other and to the larva are changing in a realistic way (see Fig. 4). This approach differs from an earlier analysis of turbulence on $E$ and net energy gain (Galbraith et al. 2004), which assumed that turbulence advects the larvae, but not the prey. These authors simulated turbulence by adding at each time step a random velocity of $5 \mathrm{~mm} \mathrm{~s}^{-1}$ to the predator while keeping the prey fixed in space. The final result is therefore a translation of the prey field relative to the predator at each time step, and is analogous to a larva moving through a 'frozen field' of prey.

\section{Influence of search volume geometry on larval feeding in nature}

It is unknown which search-volume geometry larvae use in nature; there are still no direct observations of larval fish feeding behaviour (i.e., E, pursuit success, reaction distances) in the field (MacKenzie 2000), and only a few observations of larval fish feeding behaviour in turbulent environments in the laboratory (Munk \& Kiørboe 1985, Munk 1995, MacKenzie \& Kiørboe 1995, 2000, Utne-Palm \& Stiansen 2002). In nature, where turbulence is a common feature of larval habitats, prey will approach larvae from a wide variety of angles due to the randomly directed nature of the velocity fluctuations associated with the turbulence. As a result, and especially in field situations where ingestion rates often are food-limited, there may be strong selection for larvae to be able to react to prey approaching them from a variety of directions. Such an ability may be one of several behavioural adjustments that allow fish larvae to increase search and clearance rates when they are hungry and when food is limiting (Munk 1995). We note that under some situations, a wedge-shaped search volume projected from each of the larval eyes could yield a shape approximating a hemisphere: detection angles measured for cod larvae nearly define a hemisphere volume (von Herbing \& Gallager 2000).

Our comparisons of model- and field-derived ingestion rates for cod larvae on Georges Bank in 19931994 suggest that larvae could only grow at observed rates (given other controlling factors such as prey concentration, temperature and photoperiod) if they were hemispherical searchers and were able to encounter and capture relatively large prey. Given the concentrations of preferred prey in these years (primarily Pseudocalanus sp. nauplii and copepodites, Lough et al. 2005), wedge-shaped searchers would grow much slower and presumably suffer higher mortality rates, even if they were able to locate and capture large prey. Moreover, an estimate of gross growth efficiency for the wild cod larvae on Georges Bank during 19931994 (ca. 26\%, L. Buckley pers. comm.) is lower than that assumed in our comparisons (33\%). The lower growth efficiency and the (unlikely) assumption that larval feeding always occurred at a combination of turbulence and light which maximized ingestion rates, implies an even higher requirement for prey than we have estimated. These considerations suggest to us that the larvae observed during the Georges Bank field study most likely employed hemisphere search volumes. The larvae could also attain the observed growth rates using hemisphere search geometry and by switching to consumption of smaller prey and other species in addition to Pseudocalanus. However, the available gut content data for this study shows that diets were dominated by Pseudocalanus, so we consider this possible modification of feeding behaviour unlikely.

We do not exclude the possibility that larvae can employ wedge search geometries under some circumstances; for example, if larvae are able to detect prey at much larger distances ( $>1$ larval length, as some of the cod larvae were able to do in experiments by von Herbing \& Gallager 2000), and/or if prey concentrations are much higher than we have assumed, it could be possible for larvae to encounter and capture sufficient prey to meet the observed growth rates in the field.

\section{Future prospects}

There are relatively few studies of larval fish feeding behaviour in turbulent environments and even fewer where the turbulence has been quantified (Dower et al. 1997, MacKenzie 2000). The number of species 
used in these studies is small (2: cod and herring), and from boreal-temperate habitats. Many aspects of larval feeding behaviour still require further investigation (e.g. direct visual observation in laboratory or natural environments, ontogenetic changes) and the number of species for which observations in quantified turbulence are available should be increased.

We have applied our model to simulate feeding behaviour in a simple food environment in order to understand the specific interaction of a larval fish predator with its prey. Larvae were exposed to a single prey species which was initially randomly distributed and in an environment where light was assumed to be optimal for larval feeding. Moreover, prey were not assigned any predator detection and escape behaviour, even though theoretical and experimental studies demonstrate that zooplankters exhibit such behaviours (Visser 2001, Fiksen \& MacKenzie 2002). We are aware that in nature all of these factors complicate attempts to model and understand larval fish feeding rates. For example, prey concentrations are strongly affected by storms and other turbulence-generating processes and larvae do alter their vertical distributions depending on wind speed (Heath et al. 1988, Porter et al. 2005). Larval behaviour which leads to avoidance of strong surface turbulence could be a direct reaction to the high relative velocities associated with strong mixing, or could be a response to a change in the vertical distribution of prey (Franks 2001), whose vertical distributions themselves are sensitive to turbulence intensity (Visser et al. 2001, Incze et al. 2001). Moreover, recent statistical analyses of the interaction between larval feeding, vertical distribution, turbulence and light intensity in the sea shows that if a high turbulence event occurs during daylight hours under cloudy conditions, larval feeding rates will decrease (Porter et al. 2005). If, instead, the turbulence event occurs during well-lit conditions (e.g. under clear skies), then feeding rates will remain high or even increase, because light conditions, turbulence levels and prey concentrations at depth will be closer to values which optimize larval feeding success. These complex interactions are likely partly responsible for the contrasting results of many field studies investigating how turbulence affects larval feeding in nature (MacKenzie 2000).

In the future, we will apply our modelling approach to investigate some of the higher-order interactions described above. The individual-based, objectoriented methodology can easily incorporate, for example, prey detection and escape behaviour and assign different behaviours to different sizes and species of prey. These behaviours are important mechanisms which differ among larval fish species and which nonetheless lead to the dominance of larval diets by a relatively few species (Munk 1995, Hill- gruber et al. 1997, Heath \& Lough 2007). Our modelling approach can potentially enable us to investigate how larval diets in the field change depending on prey characteristics and turbulence conditions (Dower et al. 1998, Hillgruber \& Kloppmann 2000, Fiksen \& MacKenzie 2002). Future climate change will affect not only the spatial and temporal pattern of exposure of larvae to wind and tidally induced turbulence, but will also affect the relative timing of production of individual species of zooplankton (Edwards \& Richardson 2004) and larval fish (Greve et al. 2005). Investigations of processes which affect larval fish-zooplankton interactions in environments with varying turbulence and light will increase our understanding of how larval fish locate and ingest their prey in nature, and how these processes will be influenced by expected climate changes.

Acknowledgements. This work is a contribution to a European Network of Excellence on Ocean Ecosystems Analysis (www.eur-oceans.org) and GLOBEC. P.M. was supported by a EUR-OCEANS postdoctoral fellow grant and by the Danish Institute for Fisheries Research (Departments of Marine Ecology and Aquaculture, and Sea Fisheries) and the Stazione Zoologica 'Anton Dohrn' (Napoli, Italy). We thank Dr. F. Köster for assistance and Drs. L. J. Buckley, R. G. Lough and M. Peck for discussions regarding larval cod growth and feeding on Georges Bank. An earlier version of this work was presented at the 'Workshop on advancements in modelling physical-biological interactions in fish early-life history: recommended practices and future directions,' Nantes, France, April 3-5, 2006 (co-chairs Alejandro Gallego, Elizabeth North and Pierre Petitgas).

\section{LITERATURE CITED}

Bakun A (1996) Patterns in the ocean: ocean processes and marine population dynamics. California Sea Grant System, NOAA and Centro de Investigaciones Biologicas del Noroeste, LaJolla, CA

Blaxter JHS (1986) Development of sense organs and behaviour of teleost larvae with special reference to feeding and predator avoidance. Trans Am Fish Soc 115:98-114

Browman HI, O'Brien WJ (1992) Foraging and prey search behaviour of golden shiner (Notemigonus crysoleucas) larvae. Can J Fish Aquat Sci 49(4):813-819

Buckley LJ, Durbin E (2006) Seasonal and inter-annual trends in the zooplankton prey and growth rate of Atlantic cod (Gadus morhua) and haddock (Melanogrammus aeglefinus) larvae on Georges Bank. Deep-Sea Res II 53: 2758-2770

Buckley LJ, Caldarone EM, Lough RG (2004) Optimum temperature and food-limited growth of larval Atlantic cod (Gadus morhua) and haddock (Melanogrammus aeglefinus) on Georges Bank. Fish Oceanogr 13:134-140

Caparroy P, Thygesen UH, Visser AW (2000) Modelling the attack success of planktonic predators: patterns and mechanisms of prey size selectivity. J Plankton Res 22(10): 1871-1900

Davis CS (1984) Predatory control of copepod seasonal cycles on Georges Bank. Mar Biol 82(1):31-40 
Dower JF, Miller TJ, Leggett WC (1997) The role of microscale turbulence in the feeding ecology of larval fish. Adv Mar Biol 31:169-220

Dower JF, Pepin P, Leggett WC (1998) Enhanced gut fullness and an apparent shift in size selectivity by radiated shanny (Ulvaria subbifurcata) larvae in response to increased turbulence. Can J Fish Aquat Sci 55:128-142

Edwards M, Richardson AJ (2004) Impact of climate change on marine pelagic phenology and trophic mismatch. Nature 430:881-884

Fiksen Ø, MacKenzie BR (2002) Process-based models of feeding and prey selection in larval fish. Mar Ecol Prog Ser 243:151-164

Franks PJS (2001) Turbulence avoidance: an alternate explanation of turbulence-enhanced ingestion rates in the field. Limnol Oceanogr 46(4):959-963

Fung $\mathrm{CH}$, Vassilicos JC (1998) Two-particle dispersion in turbulent like flows. Physiol Rev E 57:1677-1690

Fung CH, Hunt JCR, Malik NA, Perkins RJ (1992) Kinematic simulation of homogeneous turbulence by unsteady random Fourier modes. J Fluid Mech 236:281-318

Galbraith PS, Browman HI, Racca RG, Skiftesvik AB, SaintPierre JF (2004) Effect of turbulence on the energetics of foraging in Atlantic cod Gadus morhua larvae. Mar Ecol Prog Ser 281:241-257

Gargett AE (1989) Ocean turbulence. Annu Rev Fluid Mech 21:419-451

Gerritsen J, Strickler JR (1977) Encounter probabilities and community structure in zooplankton: a mathematical model. J Fish Res Board Can 34:73-82

Greve W, Prinage S, Zidowitz H, Nast J, Reiners F (2005) On the phenology of North Sea ichthyoplankton. ICES J Mar Sci 62:1216-1223

Hamner WM, Jones MS, Carleton JH, Hauri IR, Williams D (1988) Zooplankton, planktivorous fish, and water currents on a windward reef face: Great Barrier Reef, Australia. Bull Mar Sci 42(3):459-479

Heath MR, Lough RG (2007) A synthesis of large-scale patterns in the planktonic prey of Dietary dominance of larval and juvenile cod. Fish Oceanogr 16(2):169-185

Heath MR, Henderson EW, Baird DL (1988) Vertical distribution of herring larvae in relation to physical mixing and illumination. Mar Ecol Prog Ser 47:211-228

Helle K (2000) Does the midnight sun increase the feeding rate and hence the growth rate of early juvenile ArctoNorwegian cod Gadus morhua in the Barents Sea? Mar Ecol Prog Ser 197:293-297

Hill PS, Nowell ARM, Jumars PA (1992) Encounter rate by turbulent shear of particles similar in diameter to the Kolmogorov scale. J Mar Res 50:643-668

Hillgruber N, Kloppmann M (2000) Vertical distribution and feeding of larval blue whiting in turbulent waters above Porcupine Bank. J Fish Biol 57(5):1290-1311

Hillgruber N, Kloppmann M, Wahl E, von Westernhagen $\mathrm{H}$ (1997) Feeding of larval blue whiting and Atlantic mackerel: a comparison of foraging strategies. J Fish Biol 51(Suppl A):230-249

Houde ED (1989) Comparative growth, mortality and energetics of marine fish larvae: temperature and implied latitudinal effects. Fish Bull 87:471-496

Incze LS, Hebert D, Wolff N, Oakey N, Dye D (2001) Changes in copepod distributions associated with increased turbulence from wind stress. Mar Ecol Prog Ser 213:229-240

Jenkinson IR (1995) A review of two recent predation-rate models: the dome-shaped relationship between feeding rate and shear rate appears universal. ICES J Mar Sci 52:605-610
Kiørboe T (1993) Turbulence, phytoplankton cell size, and the structure of pelagic food webs. Adv Mar Biol 29:1-72

Kiørboe T, Munk P (1986) Feeding and growth of larval herring, Clupea harengus, in relation to density of copepod nauplii. Environ Biol Fish 17(2):133-139

Kraichnan RH (1970) Diffusion by a random velocity field. Phys Fluids 13(1):22-31

Landry F, Miller TJ, Leggett WC (1995) The effects of smallscale turbulence on the ingestion rate of fathead minnow (Pimephales promelas) larvae. Can J Fish Aquat Sci 52: $1714-1719$

Lewis DM (2003) Planktonic encounter rates in homogeneous isotropic turbulence: the case of predators with limited fields of sensory perception. J Theor Biol 222(1):73-97

Lewis DM, Bala SI (2006) Plankton predation rates in turbulence: a study of the limitations imposed on a predator with a non-spherical field of sensory perception. J Theor Biol 242(1):44-61

Lewis DM, Pedley TJ (2000) Planktonic contact rates in homogeneous isotropic turbulence: theoretical predictions and kinematic simulations. J Theor Biol 205(3):377-408

Lewis DM, Pedley TJ (2001) The influence of turbulence on plankton predation strategies. J Theor Biol 210(3): 347-365

Lough RG, Buckley LJ, Werner FE, Quinlan JA, Pehrson Edwards K (2005) A general biophysical model of larval cod (Gadus morhua) growth applied to populations on Georges Bank. Fish Oceanogr 14:241-262

MacKenzie BR (2000) Turbulence, larval fish ecology and fisheries recruitment: a review of field studies. Oceanol Acta 23:357-375

MacKenzie BR, Kiørboe $\mathrm{T}$ (1995) Encounter rates and swimming behavior of pause-travel and cruise larval fish predators in calm and turbulent laboratory environments. Limnol Oceanogr 40(7):1278-1289

MacKenzie BR, Kiørboe T (2000) Larval fish feeding and turbulence: a case for the downside. Limnol Oceanogr 45: $1-10$

MacKenzie BR, Leggett WC, Peters RH (1990) Estimating larval fish ingestion rates: can laboratory derived values be reliably extrapolated to the wild? Mar Ecol Prog Ser 67:209-225

MacKenzie BR, Miller TJ, Cyr S, Leggett WC (1994) Evidence for a dome-shaped relationship between turbulence and larval fish ingestion rates. Limnol Oceanogr 39:1790-1799

Malik NA, Vassilicos JC (1999) A Lagrangian model for turbulent dispersion with turbulent-like flow structure: comparison with direct numerical simulation for two-particle statistics. Phys Fluids 11:1572-1580

Mariani P, Botte V, Ribera d'Alcalà M (2005) An object oriented model for the prediction of turbulence effects on planktonic contact rates. Deep-Sea Res II 52:1287-1307

Mariani P, Botte V, Ribera d'Alcalà M (in press) A numerical investigation of the impact of turbulence on the feeding rates of Oithona davisae. J Mar Syst

Matsushita K (1992) Possible importance of turbulence at the spatial scale of a larval fish visual field on feeding success. Arch Hydrobiol Beih (Ergebn Limnol) 36:109-121

McLaughlin RL, Grant JWA, Noakes DLG (2000) Living with failure: the prey capture success of young brook charr in streams. Ecol Freshw Fish 9(1-2):81-89

Monteleone DM, Peterson WT (1986) Feeding ecology of American sand lance Ammodytes americanus larvae from Long Island Sound. Mar Ecol Prog Ser 30:133-143

Munk P (1992) Foraging behaviour and prey size spectra of larval herring Clupea harengus. Mar Ecol Prog Ser 80: 149-158

Munk P (1995) Foraging behaviour of larval cod (Gadus 
morhua) influenced by prey density and hunger. Mar Biol 122:205-212

Munk P, Kiørboe T (1985) Feeding behaviour and swimming activity of larval herring (Clupea harengus) larvae in relation to density of copepod nauplii. Mar Ecol Prog Ser $24: 15-21$

Oakey NS \& Elliott JA (1982) Dissipation within the surface mixed layer. J Phys Oceanogr 12:171-185

Otterlei E, Nyhammer G, Folkvord A, Stefansson SO (1999) Temperature- and size-dependent growth of larval and early juvenile Atlantic cod (Gadus morhua): a comparative study of Norwegian coastal cod and Northeast Arctic cod. Can J Fish Aquat Sci 56:2099-2111

Peck MA, Buckley LJ, Bengtson DA (2006) Effects of temperature and body size on the swimming speed of larval and juvenile Atlantic cod (Gadus morhua): implications for individual-based modelling. Environ Biol Fish 75(4): 419-429

Pepin P, Penney RW (1997) Patterns of prey size and taxonomic composition in larval fish: are there general sizedependent models? J Fish Biol 51(Suppl A):84-100

Peters F, Marrasé C (2000) Effects of turbulence on plankton: an overview of experimental evidence and some theoretical considerations. Mar Ecol Prog Ser 205:291-306

Porter SM, Ciannelli L, Hillgruber N, Bailey KM, Chan KS, Canino MF, Haldorson LJ (2005) Environmental factors influencing larval walleye pollock Theragra chalcogramma feeding in Alaskan waters. Mar Ecol Prog Ser 302:207-217

Reynolds AM (1995) The relative dispersion of particles in isotropic homogeneous turbulence. Fluid Dyn Res 16:1-10

Rosenthal H, Hempel G (1970) Experimental studies in feeding and food requirements of herring larvae (Clupea harengus L.). In: Steele JH (ed) Marine food chains. Oliver \& Boyd, Edinburgh, p 344-364

Rothschild BJ, Osborn TR (1988) Small-scale turbulence and plankton contact rates. J Plankton Res 10:465-474

Simpson JH, Crawford WR, Rippeth TP, Campbell AR, Cheok JVS (1996) The vertical structure of turbulent dissipation

Editorial responsibility: Matthias Seaman (Assistant Editorin-Chief), Oldendorf/Luhe, Germany in shelf seas. J Phys Oceanogr 26(8):1579-1590

Sundby S, Fossum P (1990) Feeding conditions of Arctonorwegian cod larvae compared with the RothschildOsborn theory on small-scale turbulence and plankton contact rates. J Plankton Res 12:1153-1162

Tennekes HH, Lumley JL (1972) A first course in turbulence. MIT Press, Cambridge, MA

Thorpe SA (2004) Recent developments in the study of ocean turbulence. Annu Rev Earth Planet Sci 32:91-109

Utne-Palm AC, Stiansen JE (2002) Effect of larval ontogeny, turbulence and light on prey attack rate and swimming activity in herring larvae. J Exp Mar Biol Ecol 268(2): $147-170$

Visser AW (2001) Hydromechanical signals in the plankton. Mar Ecol Prog Ser 222:1-24

Visser AW, Jackson GA (2004) Characteristics of the chemical plume behind a sinking particle in a turbulent water column. Mar Ecol Prog Ser 283:55-71

Visser AW, Saito H, Saiz E, Kiørboe T (2001) Observations of copepod feeding and vertical distribution under natural turbulent conditions in the North Sea. Mar Biol 138(5): 1011-1019

von Herbing IH, Gallager SM (2000) Foraging behavior in early Atlantic cod larvae (Gadus morhua) feeding on a protozoan (Balanion sp.) and a copepod nauplius (Pseudodiaptomus sp.). Mar Biol 136(3):591-602

Werner FE, MacKenzie BR, Perry RI, Lough RG, Naimie CE, Blanton BO, Quinlan JA (2001) Larval trophodynamics, turbulence, and drift on Georges Bank: a sensitivity analysis of cod and haddock. Sci Mar 65(Suppl. 1):99-115

Yamazaki H, Osborn TR, Squires KD (1991) Direct numerical simulation of planktonic contact in turbulent flow. J Plankton Res 13(3):629-643

Yamazaki H, Squires KD, Strickler JR (2004) Can turbulence reduce the energy costs of hovering for planktonic organisms? In: Seuront L, Strutton PG (eds) Handbook of scaling methods in aquatic ecology-measurement, analysis, simulation. CRC Press, Boca Raton, FL, p 493-505

Submitted: December 6, 2006; Accepted: June 5, 2007 Proofs received from author(s): September 12, 2007 